\title{
Forecasting on Ecological Security of Zhalong Wetland Nature Reserve based on Gray Theory
}

\author{
Yuqi Wang ${ }^{1,2}$, Dongke $\mathrm{Lv}^{2}$ and Zhenglin Sun ${ }^{1 *}$ \\ ${ }^{I}$ Northeast Forestry University, No.26, Hexing RD., Xiangfang Dist., Harbin, \\ China \\ ${ }^{2}$ Northeast Petroleum University, Fazhan RD., High-tech development zone, \\ Daqing, China \\ E-mail:18633533697@163.com;zhenglinsun@aliyun.com
}

\begin{abstract}
Based on field survey data and statistics of Zhalong wetland natural reserve, gray correlation model was used to comprehensively analyze and forecast ecological security of zhalong. According to "Response -Pressure - State" model, a eco-security assessment system was built which contains 32 indictors such as human activities, regional development index, etc. The results showed that: Zhalong Wetland ecological security index varied from 0.6852-0.7951 from 2015-2022. The index of ecological security alternated "safer" from "early warning". Upward trend of ecological security benefited from implementation of policies from the response subsystem.
\end{abstract}

Keywords: ecological security, Zhalong wetland, gray theory

\section{Introduction}

In recent years, with more frequent human activities, ecosystem vulnerability of Zhalong Wetland Nature Reserve appeared constantly: ecological water demand gap continues to increase, biodiversity sharp decrease, the degree of eutrophication grows. Series of environmental problems gives a red light to Zhalong Wetland ecological security. What level is Zhalong Wetland ecological security? Which environmental factors are the most prominent in Zhalong Wetland ecological security? These questions have become urgent problems to be revealed.

\section{Site and Methods}

\subsection{Site Description}

Zhalong National Nature Reserve $\left(46^{\circ} 48^{\prime} \sim 47^{\circ} 31^{\prime} 5\right.$ N, $123^{\circ} 51^{\prime} 5$ "-124 $34^{\circ} 5^{\prime \prime}$ E) is located in western part of Heilongjiang Province, the junction of Qiqihar city, Lindian, Dumont and Tailai County. It is wetland ecosystem nature reserves with a total area of $2100 \mathrm{k} \mathrm{m}^{2}$, the average years of wetland area of $1240 \mathrm{~km}^{2}$ [1]. It is the largest wetland ecological type national Nature Reserve to protect the cranes and other large water birds as the main rare bird sanctuary which plays an extremely important role in rare waterfowl protection and breeding in the world [2]. The population of the area is about 5.8-6 million people.

The annual average temperature of Zhalong Nature Reserve is $3.5^{\circ} \mathrm{C}$. The average annual rainfall is $420 \mathrm{~mm}$. The most precipitation month is July with average rainfall of $138 \mathrm{~mm}$, and minimum monthly precipitation is in January with average rainfall of $1.3 \mathrm{~mm}$. The annual average wind speed is $3.5 \mathrm{~m} / \mathrm{s}$ (three). The average annual sunshine

${ }^{*}$ Corresponding Author 
is about $2864 \mathrm{~h}$, accounting for $64 \%$ of duration of possible sunshine. The average annual evaporation is $1489 \mathrm{~mm}$. Of which the maximum month is May with the average evaporation of $279 \mathrm{~mm}$, accounting for $19 \%$ of the year; the minimum is in January, with average evaporation of $11 \mathrm{~mm}$, accounting for $0.7 \%$ of the year [3].

Mainly favorable weather conditions in Zhalong contain: fast warmer spring and adequate light are conducive to the early bird breeding live; summer water and heat simultaneously, flourish reed grass help the chicks grow; the rich food chain in autumn is good for bird wintering and migration. Disadvantage weather conditions are drought, in addition to spring drought. The frequency of drought happened in summer was up to $30 \%$ due to spatial and temporal rainfall distribution was not appropriate. In most case, after a severe drought year, it would often need 2-3 years with high precipitation to alleviate the drought situation significantly.

\subsection{Modeling Approach}

(1) Identification of Indicators: 32 assessment indictors were built in "Response Pressure - State" model, and calculated the weight of each index in the study. In the end, 3 indicators with greater weights were chosen from three systems, respectively which were main objects for assessing the eco-security. The 9 gray relational evaluation indictors were: regional development index, human activities intensity, pesticide utilization, biomass, primary productivity, water quality index, sewage treatment rate, policies and regulations, wetland management.

\section{(2) Construction of Grey Forecasting Model GM $(1,1)[4]$}

The advantage of $\operatorname{GM}(1,1)$ is less historical data demand and good imitative effect for clear trend. According to the known original time series data, the result was accumulated to enhance the regularity of data, to obtain a cumulative generating sequence. Then system of linear equations was built using both former to get GM $(1,1)$ model. And last the residual examination and residual after inspection was conducted to precision test the values from GM $(1,1)$.

Settling time response function to obtain model. $\operatorname{GM}(1,1)$.

Gray Differential: $x^{(0)}(k)+a z^{(1)}(k)=b$

Where $x^{(0)}(k) —$ gray Reciprocal, corresponding to $\frac{d x^{(1)}}{d t}$

$$
z^{(1)}(k) \ldots \text { Background value, corresponding to } x^{(1)}(t)
$$

a-development index;

$\mathrm{b}$ _ actuating quantity, parameter of differential equation.

$G M(1,1)$ differential equation is corresponding to first-order linear differential equations:

$$
\frac{d x^{(1)}}{d t}+a x^{(1)}=b
$$

Residual test use residuals directly to compare the absolute residuals and relative residuals in each time, which is a very effective arithmetic test.

Taking $k=0,1,2, \cdots,(n-1)$ back to $\hat{x}^{(1)}(k+1)$, transformation series was obtained: 
$\hat{x}^{(0)}(k+1)=\hat{x}^{(1)}(k+1)-\hat{x}^{(1)}(k)$

(3)

Where: $\hat{x}^{(0)}(k+1)$ - values of $x^{(0)}(k+1)$

Calculate the residual relative value by formula (4)

$q^{(0)}(k)=\frac{x^{(0)}(k)-\hat{x}^{(0)}(k)}{x^{(0)}(k)} \%=\frac{\varepsilon(k)}{x^{(0)}(k)} \%$

Where: $q^{(0)}(k)$ - residual relative value;

$$
\varepsilon(k) \text { - residual }
$$

Average residual: $q($ avg $)=\frac{1}{n-1} \sum_{k=2}^{n}\left|q^{(0)}(k)\right| 100 \%$

(5)

Average accuracy: $p^{\circ}=[1-q(a v g)] 100 \%$

$p^{\circ}>90 \%$ for qualified

After residual test:After residuals was used to obtain value $\mathrm{C}$ and $\mathrm{P}$ for determining GM $(1,1)$ model accuracy. The formula required as follows:

$S_{0}^{2}=\sum_{k=1}^{n}\left(x^{(0)}(k)-\bar{X}^{(0)}\right)^{2}$

$S_{0}=\sqrt{\frac{S_{0}^{2}}{n-1}}$

Where: $S_{0}$ —average variance of original series;

$x^{(0)}(k)$-original series; $\bar{X}^{(0)}$-----average of original series

$S_{1}^{2}=\sum_{k=1}^{n}\left(\varepsilon^{(0)}(k)-\bar{\varepsilon}^{(0)}\right)^{2}$

$S_{1}=\sqrt{\frac{S_{1}^{2}}{n-1}}$

Where: $S_{1}$---- average variance of residuals;

$$
\varepsilon^{(0)}(k) \text {-residuals series; } \bar{\varepsilon}^{(0)} \text { —average of residuals series }
$$

Variance ratio is $C=\frac{S_{1}}{S_{0}}$, the formula of Small error probability is:

$P=\left\{\left|\varepsilon^{(0)}(k)-\bar{\varepsilon}^{(0)}\right|\left\langle 0.6813 S_{0}\right\}\right.$ 
According to Table 1 , the accuracy of the value of $\operatorname{GM}(1,1)$ can be determined. The smaller the better for $C$ value, larger of $C$ illustrates that the original data large degree of dispersion with poor regularity of data. While $\mathrm{C}$ value was small showing the small prediction error dispersion [5]. The maximum is no more than 0.65 for general requirements. $P$ value is greater indicates smaller error probability is great, which show a higher model accuracy (Table1).

Table 1. The Division Standard of the Forecast Precision Grade

\begin{tabular}{ccc}
\hline$P$ & $C$ & Model accuracy grade \\
$>0.95$ & $<0.35$ & good \\
$>0.80$ & $<0.50$ & qualified \\
$>0.70$ & $<0.65$ & barely qualified \\
$\leq 0.70$ & $\geq 0.65$ & disqualified \\
\hline
\end{tabular}

Statistical data from 2007 to 2012 year of Zhalong Wetland Nature Reserve was selected as an indicator to predict the ecological safety. Taking sewage treatment rate as an example, the predicted value of the corresponding years was obtained by means of GM (1.1). Upon examination, the average residual $\varepsilon(k)$ was $4.13 \%$, average accuracy $q^{0}(k) \%$ was $93.65 \%$, value $\mathrm{C}$ was 0.1524 , value $\mathrm{P}$ was 1 , which were both in the allowable range of model accuracy (Table2).

Table 2. Forecasts of Sewage Treatment Rate (2009-2014)

\begin{tabular}{lllll}
\hline & Actual value & Predicted value & $\varepsilon(k)$ & $q^{0}(k) \%$ \\
\hline 2009 & 0.0651 & 0.0637 & 19.04 & 0.84 \\
2010 & 0.0678 & 0.0652 & 83.71 & 6.53 \\
2011 & 0.0631 & 0.0598 & -68.04 & -3.16 \\
2012 & 0.0546 & 0.0574 & -52.07 & -4.07 \\
2013 & 0.0631 & 0.0684 & -87.54 & -1.32 \\
2014 & 0.0647 & 0.0672 & 50.24 & 0.31 \\
\hline
\end{tabular}

\section{Result and Discuss}

\subsection{Analysis of the Overall Trend of Ecological Security in Zhalong}

Statistical data from 2007 to 2012 year of Zhalong Wetland Nature Reserve was selected as an indicator to predict the ecological safety from 2015 to 2022. The data of nine indicators were as follows (Table 3).

Table 3. Predicted Results of Ecological Security Assessment Index (20152022)

\begin{tabular}{|c|c|c|c|c|c|c|c|c|c|}
\hline \multirow{2}{*}{ mber $^{\mathrm{Nu}}$} & \multirow{2}{*}{ Index name } & \multicolumn{2}{|l|}{2} & \multicolumn{2}{|l|}{2} & \multicolumn{2}{|l|}{2} & \multicolumn{2}{|l|}{2} \\
\hline & & 015 & 016 & 017 & 018 & 019 & 020 & 021 & 022 \\
\hline$C 1$ & b & 0 . & 0 . & 0. & 0 . & 0 . & 0. & 0 . & 0. \\
\hline $\mathrm{C}_{1}$ & human activities intensity & 0301 & 0338 & 0289 & 0312 & 0319 & 0322 & 0377 & 0319 \\
\hline$C 2$ & development & 0 & 0 . & 0 . & 0 . & 0 . & 0 . & 0 . & 0 . \\
\hline $\mathrm{C}_{2}$ & index & 0534 & 0511 & 0517 & 0512 & 0518 & 0519 & 0517 & 0515 \\
\hline $\mathrm{C} 3$ & pesticide utilization & 0. & 0 . & 0 . & 0 . & 0. & ${ }^{0 .}$ & 0. & 0. \\
\hline & & $\begin{array}{r}0298 \\
0 .\end{array}$ & $\begin{array}{r}0211 \\
0 .\end{array}$ & $\begin{aligned} 036 / & \\
0 . & \end{aligned}$ & $\begin{array}{r}0351 \\
0 .\end{array}$ & $\begin{array}{r}0319 \\
0 .\end{array}$ & $\begin{array}{r}0348 \\
0 .\end{array}$ & $\begin{array}{r}0361 \\
0 .\end{array}$ & $\begin{array}{r}0302 \\
0 .\end{array}$ \\
\hline $\mathrm{C} 4$ & Primary productivity & 0314 & 0318 & 0315 & 0327 & 0351 & 0351 & 0381 & 0351 \\
\hline $\mathrm{C} 5$ & water quality index & $0219^{0}$ & $0238^{0 .}$ & $0253^{0 .}$ & 0. & $0238^{0 .}$ & $0214^{0 .}$ & $021^{0 .}$ & $0238^{0 .}$ \\
\hline C6 & biomass & 0. & 0 . & 0 . & 0 . & 0 . & 0. & 0 . & 0 . \\
\hline
\end{tabular}




\begin{tabular}{ccccccccccc}
\hline & & 0327 & 0543 & 0539 & 0518 & 0512 & 0509 & 0503 & 0512 \\
C7 & sewage treatment rate & 0. & 0. & 0. & 0. & 0. & 0. & 0. & 0. \\
& & 0734 & 0749 & 0771 & 0788 & 0718 & 0769 & 0752 & 0712 \\
& & 0. & 0. & 0. & 0. & 0. & 0. & 0. & 0. \\
C8 & policies and regulations & 0237 & 0261 & 0291 & 0306 & 0315 & 0352 & 0359 & 0327 \\
& & 0. & 0. & 0. & 0. & 0. & 0. & 0. & 0. \\
C9 & wetland management & 0342 & 0359 & 0395 & 0413 & 0469 & 0467 & 0421 & 0411 \\
& & 0. & 0. & 0. & 0. & 0. & 0. & 0. & 0. \\
SI & Degree of eco-security & 6852 & 7004 & 7381 & 7507 & 7632 & 7786 & 7853 & 7951 \\
\hline
\end{tabular}

According to indicator data, the degree of eco-security of the reserve could be obtained for corresponding years. The development trend of ecological security was drawn combined with calculating results from 2009 to 2022 years (Figure 1).

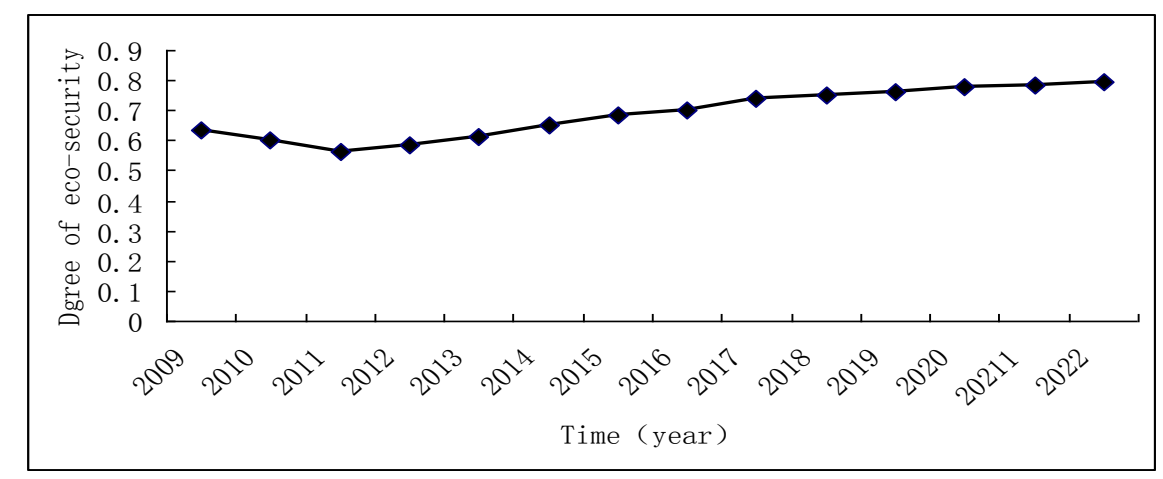

\section{Figure 1. The Dynamic Trend of Ecological Security in Zhalong}

According to the results, Zhalong wetland ecological security showed an increasing trend 2015-2022. 2015 ecological safety was in ecological security alert level with 0.6852 degree. 2016-2018 ecological safety is improved with 0.7004 and 0.7381 , respectively, which achieved the critical point of safer level. And 2018 ecological safety was in safer level of ecological security with 0.7507 degree. It indicates that the security situation is getting better gradually. The main problem that Zhalong faced such as vegetation severely degraded, number and variety of birds reduction, fish resource depletion, water pollution aggravation, etc. just because several relationships were not deal well. For example, the relationship between wetland resource protection and rational development and utilization, the relationship among current interests and long-term interests and whole interests which damaged wetland ecology. The relationship between man and nature had improved when the policy of Zhalong Nature Reserve adjusted positively to increase water resources allocation and to solve the problem of water shortage and ecological damage. So in end of the ten years in $21^{\text {st }}$ century, ecological security will reach "relatively safe" level [6].

\subsection{Prediction of Ecological Security in Subsystems of Natural Reserve}

On the basis of total SI, the interval range of subsystem SI value in each grade was divided: $\leq 0.083$ for dangerous, between $0.083-0.167$ for more dangerous, $0.167-0.25$ for warning, $0.25-0.33$ for safer and $\geq 0.33$ for safe. And the future trend of subsystem was drawn (Figure 2) [7]. As we can see, from 2009 to 2014, each subsystem was all in 3 grade "early warning". It illustrated that the over-all situation affecting ecosystem of Zhalong wetland has not been effectively improved. Pressure still existed. Especially for the climatic conditions, global warming keeps the temperature rise and causes series of environmental problems. Water evaporation of wetlands may continue to increase resulting in wetlands area reducing constantly. Security index of State subsystem showed a slowly rising trend from 2009to 2014 whose trends was similar with Response 
subsystem but a certain lagging. Especially after 2015, with the decline of Pressure subindex, the lag was obvious. Response subsystem had been an upward trend and remained above at 4 grade since 2016 [8].It fully explained that relevant authorities paid much concerned on ecological security and took effective measures to promote ecological security level of Zhalong.

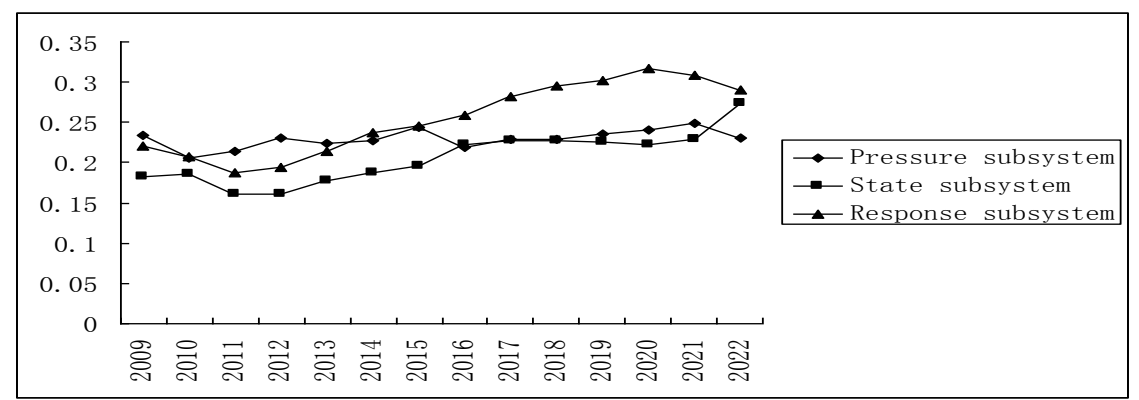

\section{Figure 2. The Subsystem Development Trend of Ecological Security in Zhalong}

\subsection{Predicting Impact Factors of Ecological Security in Natural Reserve}

In this part, we chose 2015, 2019 and 2022 respectively as the study objects to analysis the impact factors in different subsystems.

As Figure 3 showed, regional development index still the most important factor in Pressure subsystem, but trends was downward. Human activities showed obvious decreasing trend indicating that in next period time, the relevant authority may has residents moved out and resettled reasonably to protect ecosystem effectively. The impact of Beach area degradation on the ecological environment began to highlight. A part of artificial wetland including beaches began to degenerate even compaction in the reserve. The relevant departments should be concerned about this factor and take effective measures to control. The impact of pesticides and fertilizers on ecological security should not be ignored. It is worth noting that the index of ecological tourist arrivals increased year by year from 2015 to 2022 . We should pay attention to strengthen the quality of tourists on ecological and environmental awareness to make sure ecotourism can development on the healthy track, or it may be the same as the traditional tourism who become the destroyer of ecological resources.

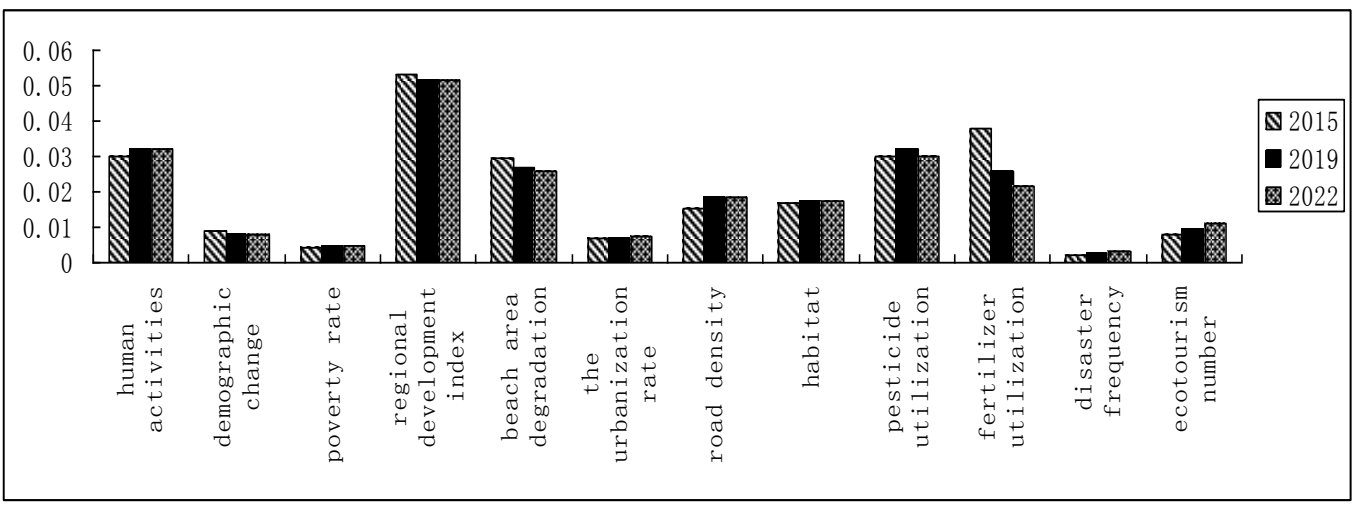

Figure 3. Trend Predictions of Factors in Pressure Subsystem

As Figure 4 showed, the top three factors of State subsystem are biomass, primary productivity and water pollution index, respectively. Biomass index had significant fluctuations with increasing first in 2019 and then declining in 2022. The changes 
showed that Zhalong wetland ecosystem has been polluted and destroyed in a long time that their biological communities were suffered a devastating blow and difficult to recover in a short time. Actually, biological diversity is very important for security ecosystem. The more complex the structure is, the better inclusive the ecosystem is responding to external stimulus. So relevant managers don't ignored biodiversity conservation and restoration owing to the long time. Water pollution remains an important environmental factor to be solved. While water pollution index increased year by year, it indicated that with the development of society, agricultural production dependent on pesticides and fertilizers more and more. It may have some control over the use of the measure, but due to the complexity of the chemical composition, it is not easy to effectively degrade the organic pollution for fragile wetland ecosystem. Besides, we noticed that landscape fragmentation factor is particularly prominent in numerous factors. Landscape fragmentation is mainly reflected in wetland nature reserve being divided by highways, natural villages and other human factors seriously. It would immediate cut off natural link between all the water and the plant community [9].

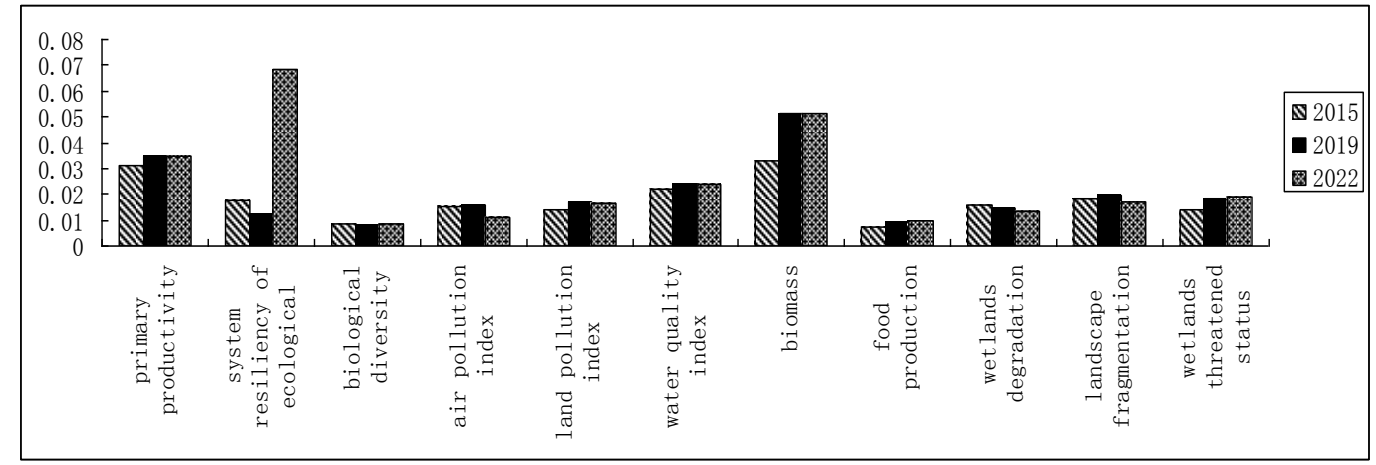

Figure 4. Trend Predictions of Factors in Pressure Subsystem

In Response subsystem, the top three factors are the sewage treatment rate, water regulation and wetlands management (Figure 5). Sewage treatment is still a top priority administration in the future, which fully indicates water eutrophication is important disturbance factor that impacts ecological security of Zhalong. Solving the problem of water shortage effectively is the key to restore wetland ecosystem. Of course, we estimate that wetlands water demand can not be fully resolved in the next period of time. Zhalong wetland is located at the junction of Qiqihar and Daqing [10]. The groundwater level of latter declined sharply due to oil exploitation for long time. Artificial replenishment for wetlands must be upheld to form a long-term mechanism. The third is wetland management level, which shows the role of wetlands management in Zhalong wetland ecological protection. Wetland management urgent needs the professionals who both understand technology and management to enrich our team to management the wetland resources with the idea of sustainable development, which we expect to see. 


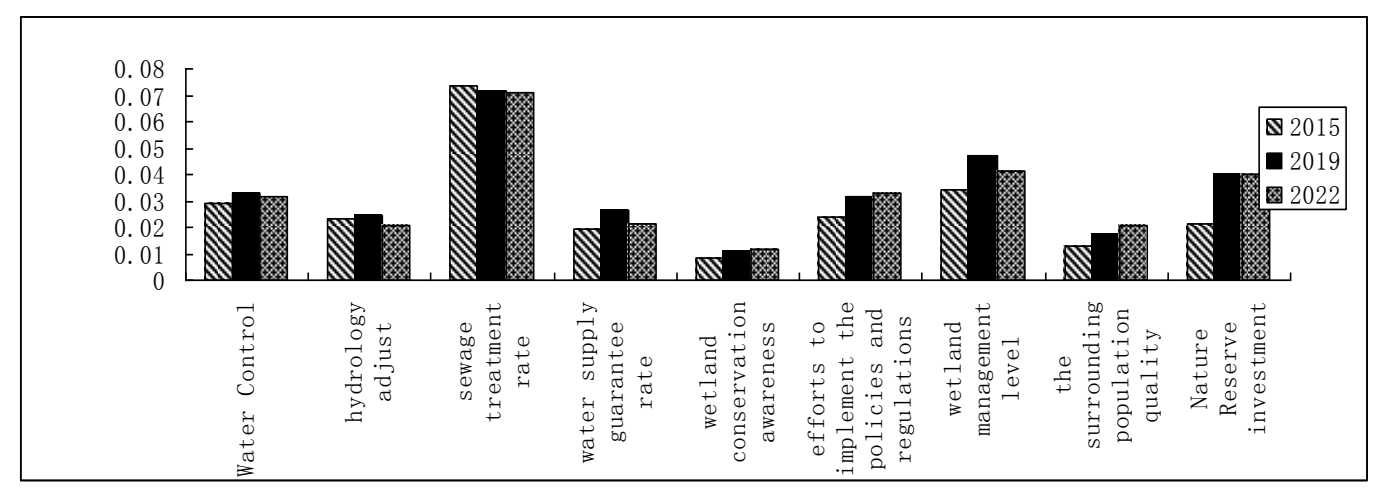

Figure 5. Trend Predictions of Factors in Respond Subsystem

\section{Conclusions}

According GM (1.1) model's predictions, we find that Zhalong Nature Reserve has been under the safety level before 2016 and ecological environment is under threat. Water shortage and water pollution are the most important factors to affect ecological security in Zhalong. The relevant management must take effective measures to solve these problems. And the increasing trend will appear after that.

\section{Acknowledgements}

This work is partially supported by post doctoral study center of Northeast Forestry University. The authors also gratefully acknowledge the helpful comments and suggestions of the reviewers, which have improved the presentation.

\section{References}

[1] Qin X. N., Lu X. L. and Wu C. Y., "The knowledge mapping of domestic ecological security research: biblimoetric analysis based on cityespace", Acta Ecologica Sinica, vol. 13, no. 34, (2014).

[2] Farhan A. R. and Lim S., "Vulnerability assessment of ecological conditions in Seribu Islands", Indonesia. Ocean and Coastal Management, vol. 65, (2012).

[3] Chen J. and Wu D. W., "Ecological security assessment of western coast of Taiwan Strait under rapid urbanization", Chinese Journal of Ecology, vol. 12, vol. 29, (2010).

[4] Yu R. R., Xie W. X., Zhao Q. S., Xu Z. and Liu W. L., "Ecological safety assessment of Dagu estuary wetland in Jiaozhou Bay of Shandong Province", East China based on landscape pattern. Chinese Journal of Ecology, vol. 11, no. 31, (2012).

[5] Kiesecker J. M., Copeland H., Pocewicz A. and McKenney B., "Development by design: blending landscape-level planning with the mitication hierarchy. Frontiers in Ecology and the Environment", (2010).

[6] Rapidel B., DeClerck F. and Le Coq J. F., "Eds. Ecosystem servies from Agriculture and Agroforestry: Measurement and Payment", Earthscan, London, (2011).

[7] J. H. Goldstein, Caldarone G., Duarte T. K., Ennaanay D., Hannahs N., Mendoza G., Polasky S., Wolny S. and Daily G. C., "Integrating ecosystem Service tradeoffs into land-use decisions", Proc. National Academy of Sciences USA., vol. 109, (2012).

[8] Ehrlich P. R., Kareiva P. and Daily G. C., "Securing natural capital and expanding equity to rescale civilization", Nature, vol. 468, (2012).

[9] Li J., Feldman M. and Li S., "Daily G C.Rural household income and inequality under payment for ecosystem services: The Sloping land Conversion Program in Western China", Proceedings of the National Academy of Sciences USA, vol. 108, (2011).

[10] Liang Y. C., Liu G., Ma D. C., Wang F. C. and Zheng H., "Regional Cooperation Mechanism and Sustainable Livelihoods: A Case Study on Paddy Land Conversion Program (PLCP)", Acta Ecologica Sinica, vol. 33, (2013). 


\section{Authors}

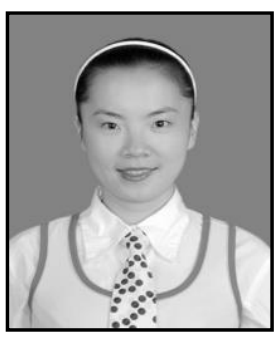

Yuqi Wang, Ph.D. in Hydrobiology from Wildlife Resources College of Northeast Forestry University. Associate professor of Northeast Petroleum University. The research interests is ecological footprint modeling and wetland ecological assessment.

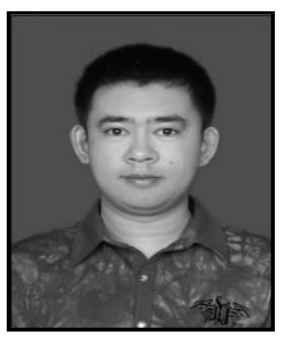

Dongke Lv., Ph.D. Associate professor of Northeast Petroleum University. Now working as a post-doctor in Northeast Agricultural University. The research interests are wetland carbon flux and wetland eco-tourism.

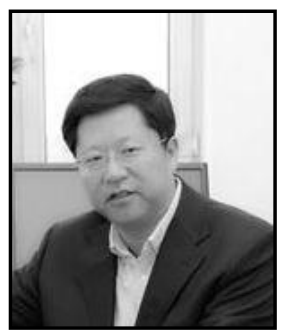

Zhenglin Sun, Doctor of management. Doctoral supervisor of Economic Management College of Northeast Forestry University. Host and participate in several Natural Science Foundation of China (NSFC). The major is forestry economic management. 
International Journal of Security and Its Applications

Vol. 10, No. 8 (2016) 